\title{
Free State Constructions
}

\author{
Thamir Al Barrag, Mohammad Al Zahrani \\ Taif University, Taif, Saudi Arabia
}

\begin{abstract}
This paper attempts to investigate Free State (FS) in Hijazi Arabic. This structure is not used in Modern Standard Arabic. It was introduced into the Arabic dialects later on as a competing structure to the Construct State (CS). First, we discuss the characteristics of this structure in comparison to its counterpart: the CS. we show that semantically FS can express only three semantic relations out of the five semantic relations CS can convey. Furthermore, the paper shows that the FS genitive exponent in HA " $\hbar$ agg" agrees with the head noun of the matrix DP in phi-features. The discussion then shifts to the origin of the genitive exponent $\hbar$ agg. The paper argues that it is originally a noun that has acquired a new meaning: an anaphor that means something like "one of". Hence, we gloss $\hbar$ agg as ANAPH. Contrary to previous analyses for the FS genitive exponent, the paper proposes that $\hbar a g g$, the noun, heads its own CS and it is linked to the preceding DP by a binding relationship, which involves feature agreement in gender and number. Consequently, we propose that $\hbar$ agg-headed CS has the same structure of the nominal CS. Finally, we investigate the occurrence of both FS and CS structures in HA and show when one structure is preferred to the other.
\end{abstract}

Keywords: syntax, Arabic, constructions, annexation, state, anaphor, minimalism

\section{Introduction}

Hijazi Arabic has been the interest of many linguists (Al Barrag, 2007; 2014; Al Zahrani, 2008; 2013; 2014a; 2014b; 2015; Feghali, 1991; Kheshaifaty, 1996; Margaret, 1975; Nydell \& Foreign Service Institute (U.S.), 1975; Sieny, 1978). These linguists have investigated many aspects of HA grammar including its basic syntactic structure, various word order options, modal system, aspect and tense, lexical aspect, negation, other morphosyntactic and semantic properties, morphological derivations, and much more. This paper tries to continue these investigations by shedding light on two structures that express possession and relationships in HA.

There are two structures to express possession or genitive relationships in Semitic languages: Construct State (CS) and Free State (FS). Modern Standard Arabic (MSA) uses only the CS structure. It is a syntactic structure that joins two nouns together, where the second noun determines the first by identifying, limiting, or defining it — that is, it is a means of creating a complex DP out of two DPs (or more). ${ }^{1}$ Ultimately, both nouns function as one phrase (Ryding, 2005). CS in Arabic is called Pi $\underline{\gamma^{\varsigma}} \mathrm{a}$ :fah "annexation or addition". The first

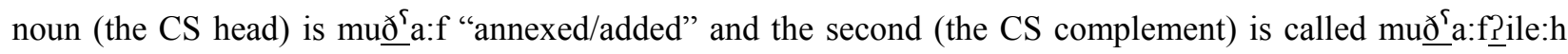
"annexed to/ added to". The CS Structure is one of the most discussed syntactic issues in the literature on

\footnotetext{
Thamir Al Barrag, assistant professor, Ph.D., Foreign Languages Department, Taif University, Taif, Saudi Arabia. Mohammad Al Zahrani, assistant professor, Ph.D., Foreign Languages Department, Taif University, Taif, Saudi Arabia.

1 The first constituent of the CS can be a noun, adjective or quantifier.
} 
Semitic languages (Al Barrag, 2014; Aoun, 1978; Bardeas, 2010; Borer, 1999; Fassi Fehri, 1993; Mohammad, 1999; Ritter, 1987; 1988; 1991; Shlonsky, 2004; Siloni, 1997).

The other Arabic dialects, on the other hand, use both structures: CS and FS. Unlike CS which joins two nouns together, FS uses a genitive exponent to connect the two nouns. Harning (1980) refers to CS and FS as synthetic versus analytic genitives based on the view that Arabic dialects have long been in the process of shifting from a synthetic language to an analytic one.

In Hijazi Arabic (HA), the use of FS is on a par with CS and conveys most of the semantic relations CS can convey. Moreover, it is often used to avoid ambiguity or resolve some of the difficulties associated with CS, as will be shown later.

In this paper, we discuss FS, the "competing" structure to CS. In the next section, the discussion is about the characteristics of the FS. A full detailed description of the structure and all that are related to it will be provided. In the process, the paper highlights what differentiates FS from CS. Finally, we describe the occurrence of these two structures in HA and account for their distribution.

\section{Characteristics of Free State}

As stated above, FS is an alternative way for expressing possession or genitive relations. However, FS cannot express all the semantic relations between the CS head and CS complement. In examples (1), CS can express five main relationships between the CS head and the complement. Basically, the complement restricts the denotation of the head. These five semantic relations are possession (1a), modification/identification (1b), action-agent (1c), action-theme (1d), and partitive/quantifier relationship (1e).

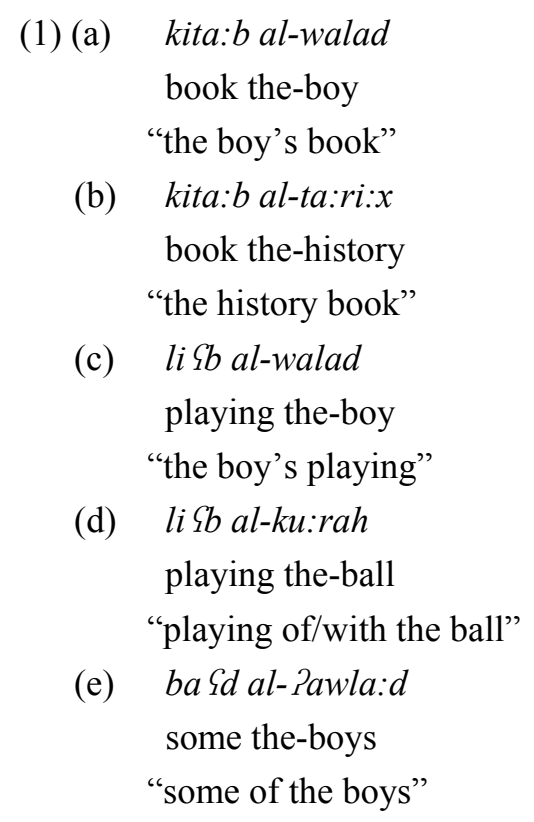

On the other hand, as shown in (2), FS can only express three of these five semantic relations: possession (2a), modification/identification (2b), and action-agent (2c). To convey the last two meanings, one must use the $\mathrm{CS}$, hence, (2d) and (2e) are ungrammatical.

(2) (a) al-kita:b hagg al-walad

the book ANAPH the-boy

"the boy's book" (lit. the book of the boy) 


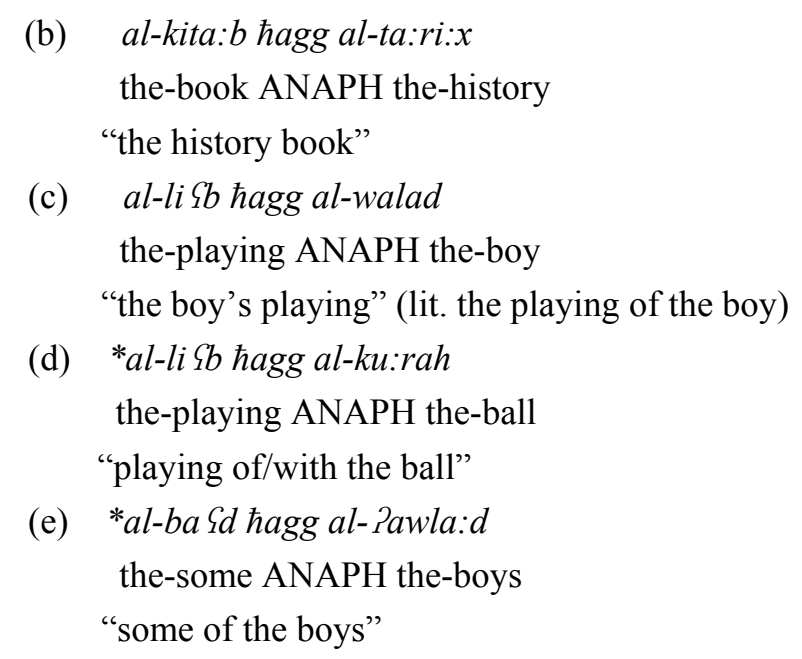

Even within the possible meanings FS can express, there are still some restrictions. Unlike CS, FS cannot express inalienable possession or kinship relations. Nor can it express human social relations, such as friends or neighbours.

(3) (a) fam al-walad

mouth the-boy

"the boy's mouth"

(b) *al-fam hagg alwalad

the-mouth ANAPH the-boy

"the mouth of the boy"

(4) (a) bint al-rijja:l

girl the-man

"the man's daughter"

(b) *al-bint hagg al-rijja:l

the-girl ANAPH the-man

"the daughter of the man"

(5) (a) $\underline{s}$ sahib al-rijja:1

friend the-man

"the man's friend"

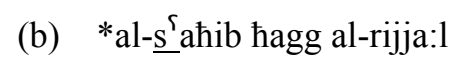
the-friend ANAPH the-man

"the friend of the man"

In (3), each phrase attempts to express inalienable possession using CS or FS. While the CS structure in (3a) is successful, the FS construction in (3b) is not. Similarly, in (4), the CS successfully expresses the kinship relation (4a) where FS cannot (4b). Finally, in (5), it can be seen that CS is able to express human social relations, such as "friend" ( $5 a)$ but the FS cannot $(6 b)$.

Structurally speaking, FS has two main properties: (1) It uses a "genitive exponent" to connect both parts of the complex DP: the head noun and the genitive noun and (2) the position of adjectives with respect to the head noun and the genitive noun is not the same as in CS, as will be shown later (Brustad, 2000; Harning, 1980; 
Ryding, 2005). The paper keeps calling the genitive exponent and genitive noun by the same names even though HA has lost case marking except with pronouns.

The main difference between CS and FS is that FS uses a genitive exponent (ћagg in HA) to join both the head and genitive nouns (e.g., Bardeas, 2010 among many others; Fassi Fehri, 1993; Ritter, 1991; Shlonsky, 2004; Siloni, 1997). The element $\hbar a g g$ has been called variously by different names by different researchers: a particle, a preposition, an adjective, or just a genitive exponent. In this paper, we consider the genitive exponent an anaphor which forms a kind of a CS that modifies or restricts the denotation of the noun in the matrix DP, as discussed below. We assume that this exponent is responsible for all structural and semantic differences as will be shown later.

Harning (1980) describes the "analytic genitive" (FS) and genitive exponent in the different Arabic dialects as a "dialectal innovation" in the sense that Classical Arabic used the "synthetic genitive" (CS) besides the genitive exponent varies in form and agreement from one dialect to another. Consider the following table (Brustad, 2000, p. 72):

Table 1

Genitive Exponent in Some Arabic Dialects

\begin{tabular}{llll}
\hline & Masculine & Feminine & Plural \\
\hline Moroccan & dya:1/ d & ---- & ---- \\
Egyptian & bita: $\complement$ & bita:Sit & bitu: $\subseteq$ \\
Syrian & taba $\subseteq$ & ---- & (taba@u:l) \\
Kuwaiti & ma:1 & (ma:lat) & (ma:lu:t) \\
\hline
\end{tabular}

According to Brustad, Egyptian Arabic is the only dialect that requires number/gender agreement. Moroccan has no agreement at all. ${ }^{2}$ There is no feminine agreement in Syrian and the plural form is optional. And in Kuwaiti, both feminine and plural forms are optional.

The HA form of this genitive exponent is hagg. It is similar to the Egyptian genitive exponent bita: $\mathcal{S}$ in that it agrees with the head noun in number and gender; therefore, it has three forms: $\hbar$ agg for masculine

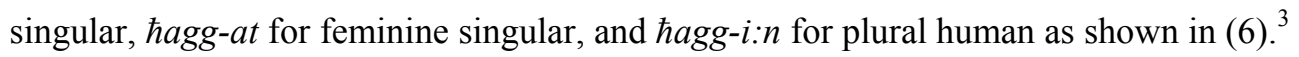

(6) (a) al-mudarris ћagg al-tari:x

the-teacher ANAPH the-history

"the (male) history teacher"

(b) al-mudarris-ah ћagg-at al-tari:x

the-teacher-F.s ANAPH-F the-history

"the (female) history teacher"

(c) al-mudarris-i:n/a:t hagg-i:n al-tari:x

the-teacher-PL/F.PL ANAPH-PL the-history

"the (male/female) history teachers"

In (6), it can be seen that the FS genitive exponent agrees in number and gender with the head noun in each case. Both the pre-hagg DP and the FS exponent in (6a) are masculine and singular; they are both feminine and singular in (6b); and in (6c), the pre- hagg DP is plural and so is the FS exponent. As for gender,

\footnotetext{
${ }^{2}$ Contrary to Brustad's Table $1(2000,72)$ which states that the Moroccan genitive exponent $d y a: l / d$ does not agree with the head noun, a native speaker has informed me that $d y a: l$ does agree in number and gender.

3 Actually, the feminine marker in HA is - ah but it becomes - at when hosted by the "head" of a CS.
} 
once the noun is plural, the agreeing constituent does not mark the gender feature of its coreferring noun. ${ }^{4}$

\section{Origin and Analysis of the Genitive Exponent " $\mathrm{hagg"}$}

Originally, the word $\hbar a g g$ is a noun in MSA which means "truth", "right", or "property"; $\hbar a g g$ is the

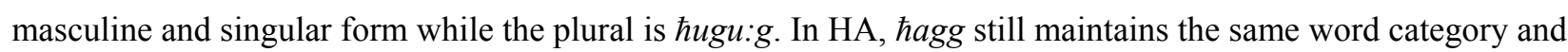
the same senses along with the new usage as a genitive exponent.

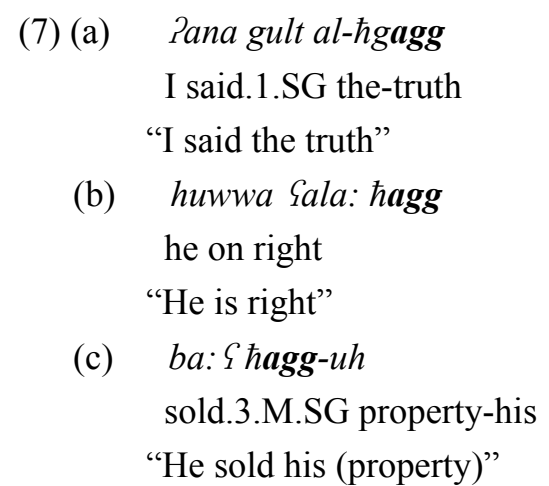

In (7), the noun hagg appears in three different sentences with three different, but related meanings: "truth" in (7a), "right" in (7b), and "property" in (7c).

In a way, the genitive exponent $\hbar a g g$ resembles adjectives that agree with the modified noun in phi-features. However, it differs from them in that it does not agree in definiteness with the noun (cannot be attached to the definite article) and it cannot be accompanied with a degree word (e.g., marrah "very/extremely"); furthermore, it does not have a comparative or superlative form. Thus, considering $\hbar a g g$ an adjective is ruled out.

Bardeas (2010) considers the HA genitive exponent a preposition. She claims that the word $\hbar a g g$ has obtained a new categorical status to its original one (i.e. noun). She argues that it has become a preposition for two reasons. First, it has a similar counterpart preposition in MSA that is used as an alternative to CS; and second, just like with prepositions, the pronoun that follows the genitive exponent is in the syncretic accusative/genitive form.

The MSA counterpart for the HA genitive exponent is the preposition $l i$ "for". This preposition expresses only possession and no other semantic relations, unlike the HA one. Besides, it shows no agreement with the genitive noun.

(8) (a) kita:b-u al-walad-ial-qadi:m-u book-NOM the-boy-GENthe-old-NOM

"the boy's old book"

(b) kita:b-u walad-i-n-qadi:m-u-n

book-NOM boy-GEN-INDEF old-NOM-INDEF

"a boy's old book"

(c) kita:b-u-nqadi:m-u-nli al-walad-i

book-NOM-INDEF old-NOM-INDEF for the-boy-GEN

"an old book of the boy"

\footnotetext{
${ }^{4}$ By "agreeing constituent" we mean a pronoun, a verb, an adjective or, as in this case, a FS exponent.
} 
(d) kita:b-u-nqadi:m-u-nli walad-n

(MSA)

book-NOM-INDEF old-NOM-INDEF for boy-GEN-INDEF

"an old book of a boy"

(e) *al-kita:b-uli al-walad-i

the-book-NOM for the-boy-GEN

"the book of the boy"

Although the meaning of the sentences in (8) is not exactly the same, MSA uses the preposition $l i$ "for" as an alternative means of conveying the possession meaning, illustrated in (8c). In (8a), the head noun kita:b "the book" has no definite article yet it is definite due to definiteness spread within the CS. Even if the CS complement is indefinite, which means the head noun will be indefinite too, kita:b "book" is still specific, as shown in (8b). However, with the preposition in $(8 \mathrm{c} \& \mathrm{~d})$, the head noun kita:b "book" is indefinite, yet it can be either specific or non-specific. Example (8e) is unacceptable with the intended meaning (i.e. phrase meaning). If kita:b "book" is definite with the preposition, it gives a clausal meaning "The book is for the boy".

In addition, Bardeas (2010) assumes that $\hbar a g g$ is a preposition because of its ability to assign genitive case to the following noun just like any preposition can. The example in (9a) contains the preposition $f i$ "in" which selects a genitive pronoun. ${ }^{5}$ In (9b), hagg "of" does the same and selects a pronoun in the genitive form. ${ }^{6}$

(9) (a) al-kita:b fi- $h$

the-book in-it

"The book is in it"

(b) al-kita:b ћagg-uh

the-book PREP-him

"his book"

As for $\hbar a g g$ 's ability to agree with the head noun, Bardeas (2010) mentions a similar case in HA. There is an expletive interrogative complementiser that agrees in number and gender with the subject of the question. It can appear at the beginning of Yes/No questions. It resembles pronouns in their form but is used as a question word. MSA uses different question words for Yes/No questions that do not agree. Consider these examples (Bardeas, 2010, p. 120):

(10) (a) hoa al-waladja? he the-boy came (3-M-SG)

"Did the boy come?"

(b) hia? oxt-akja:t? she sister (F-SG)-your (M) came (3-F-SG)

"Did your sister come?"

Considering hagg a preposition because there is in MSA a counterpart preposition and the pronoun, which can substitute the noun after $\hbar a g g$, appears in the syncretic accusative/genitive form is not enough. The so called counterpart preposition in MSA can only convey one of many semantic relationships that $\hbar a g g$ can convey (possession). The MSA preposition $l i$ "for" can only occur after an indefinite noun; otherwise a clausal meaning is obtained, as in (8). Furthermore, pronouns that act as a CS complement appear in the syncretic

\footnotetext{
${ }^{5}$ As mentioned earlier, HA has lost nominal case marking except for pronouns.

${ }^{6}$ Note that $-h$ in $(9 a)$ is an allomorph of $-u h$ in $(9 b)$.
} 
accusative/genitive form as well. In (11a), the CS consists of the CS head and a pronoun in the syncretic accusative/genitive form as its complement.

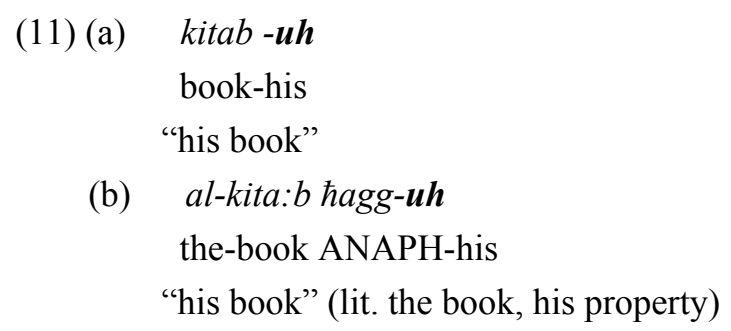

It was shown, in (7), that $\hbar$ agg is actually a noun in HA and it has three meanings: "truth", "right", or "property". We argue that $\hbar a g g$ of the FS is also a noun that has acquired a new meaning: an anaphor that means something like "one of". Also, hagg heads its own CS and it is linked to the preceding DP by a binding relationship, which involves feature agreement in gender and number, as can be seen in (6). Being in a CS structure, hagg and its complement show all CS properties: (1) no definite article on the head; (2) definiteness spread; (3) inseparable head and complement; and (4) if the head is followed by a pronoun, the pronoun appears in the syncretic accusative/genitive form. As mentioned above, when the complement is substituted with a pronoun, just like nominal CS, the pronoun appears in the syncretic accusative/genitive form- $u h$, as in (11). As an anaphor, hagg is not modified by any modifier. All modification goes directly to the antecedent

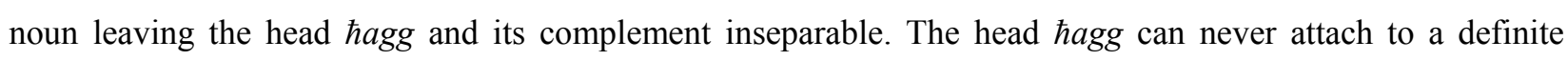
article, as in (12).

(12) (a) al-kita:b hagg al-walad the-book ANAPH the-boy

"the book of the boy" (lit. the book (the) one $_{\mathrm{i}}(\mathrm{of})$ the boy)

(b) *al-kita:b al-hagg al-walad the-book al-ANAPH the-boy

"the book of the boy"

However, it inherits definiteness from its complement: if the complement is definite, the CS is definite and can modify a definite noun, as in (13a), and if the complement is indefinite, then the CS is indefinite and it modifies an indefinite noun, kita:b "book", as in (13b).

(13) (a) [al-kita:b [ hagg al-walad $]$ the-book ANAPH the-boy

"the book of the boy" (lit. the book $\left(\right.$ the) one $\mathrm{i}_{\mathrm{i}}(\mathrm{of})$ the boy)

(b) $\quad[$ kita:b [ hagg walad $]]$

book ANAPH boy

"a book of a boy" (lit. a book one $_{\mathrm{i}}$ (of) a boy)

The second structural difference between the two structures, FC and CS, is adjective placement. In CS, all adjectives follow the genitive noun and if both nouns are modified by an adjective, the adjective that modifies the complement comes first, as in (14a). On the other hand, FS deals with adjectives differently. All adjectives that modify the head noun of the matrix DP come directly after it and those modifying the complement follow it as well, as in (14b). This is expected since al-kita:b is outside the $\hbar$ agg-headed CS phrase. Moreover, $\hbar a g g$ is an anaphor and it is the antecedent noun that is modified. 
(14) (a) $\quad$ [kita:b [al-waladal-mari: $\underline{\left.\delta^{\varsigma}\right]}$ al- $\underline{\text { yaa:li }]}$ book the-boy the-sick the-expensive "the expensive book of the sick boy"

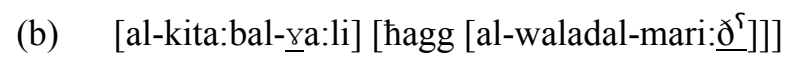
the-book the-expensive ANAPH the-boy the-sick

"the expensive book of the sick boy" (lit. the expensive book $\mathrm{k}_{\mathrm{i}}$, (the) one $\mathrm{i}_{\mathrm{i}}$ (of) the sick boy)

We so far have argued above that the FS is actually a special kind of CS that is headed by the anaphor $\hbar a g g$ and that it is linked to the preceding DP by a binding relationship, which involves feature agreement in gender and number. We propose that $\hbar$ agg-headed CS has the same structure of the nominal CS. ${ }^{7}$ A sentence as in (6c) (repeated here as (15a)) is illustrated as in as in (15b \& c).

(15) (a) al-mudarris-i:n hagg-i:n al-tari:x

the-teacher-PL ANAPH-PL the-history

"the (male/female) history teachers"

(b)

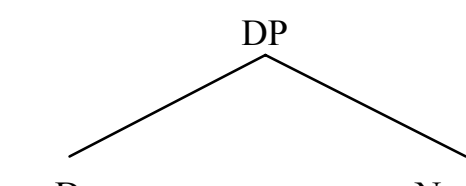

$[+\mathrm{DEF}]$

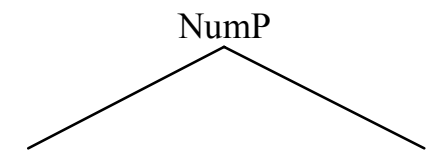

al-

Num

$[+\mathrm{PL}]$

-i:n

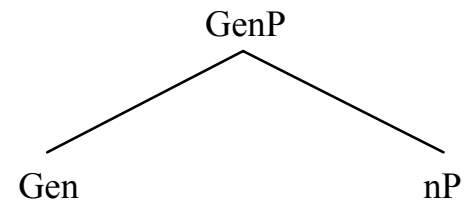

[M]

$\varnothing$

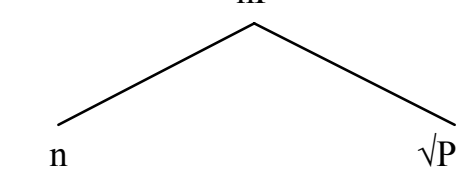

mu-a-i-

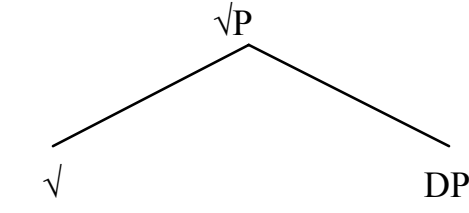

$\sqrt{D R S}$

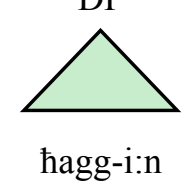

al-tari:x

${ }^{7}$ See T. Al Barrag (2014) for a detailed analysis of the HA CS. 
(c)

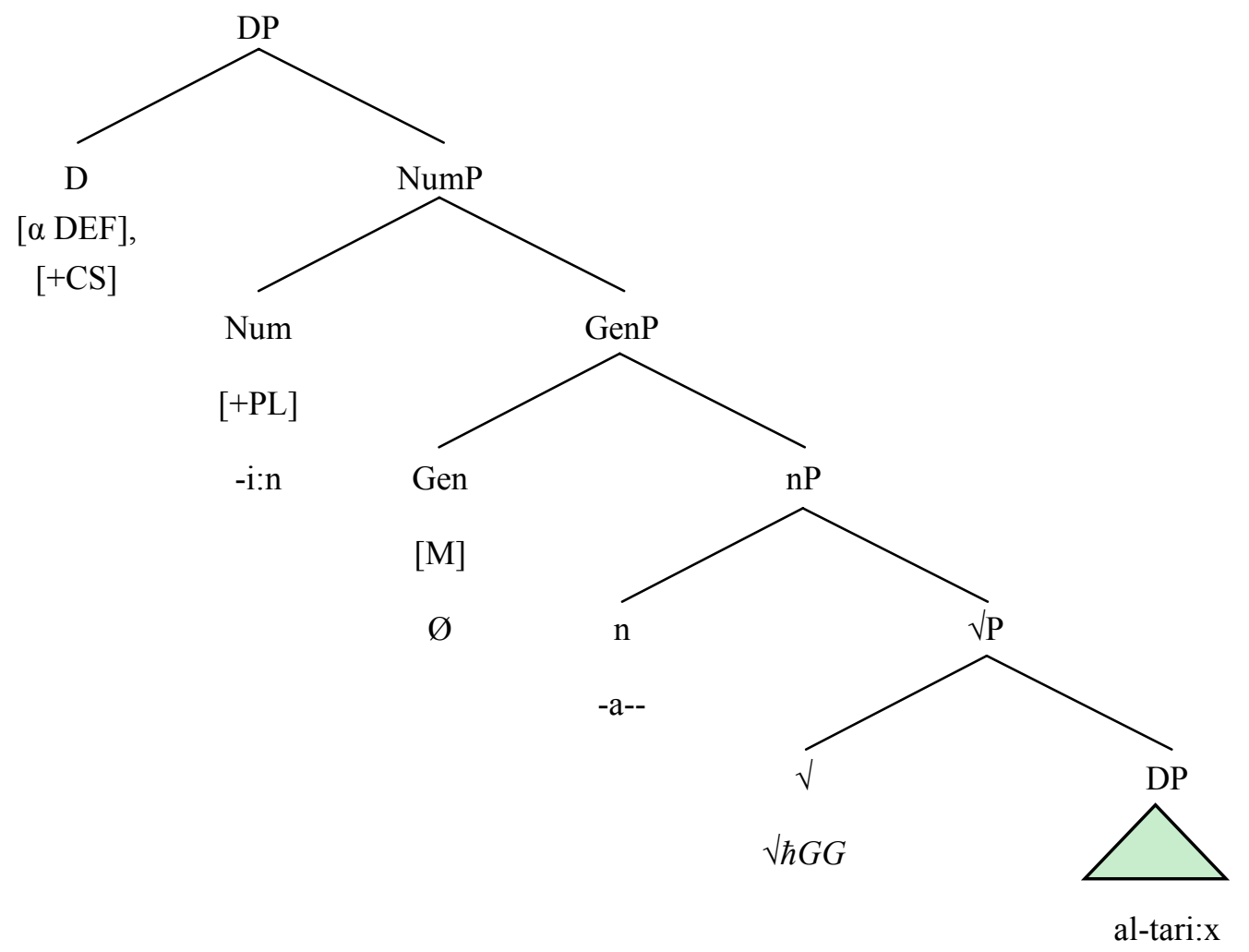

The schematic tree in (15b) represents the derivation of the whole DP and where $\hbar a g g$-headed CS is located in regard with the matrix DP. The hagg-headed CS merges with the neutral root of the matrix DP noun and the derivation proceeds from there as any simplex noun. The tree in $(15 \mathrm{c})$ represents the internal derivation of the hagg-headed CS. It shows that it is dominated by a CS D which carries the features $[\alpha \mathrm{DEF}],[+\mathrm{CS}]$. Thus, the derivation begins with the CS complement merging with the root of the head $\hbar a g g$ which merges with the (n) ominaliser, Gen, Num and finally CS D.

\section{Construct State or Free State}

In this section we address the question: Why would a speaker choose CS over FS, or vice versa? As shown above, CS is considered the primary means in MSA to express all five semantic relationships-possession, modification/identification, action-agent, action-theme, and the partitive relationship, as shown in (1). However, in HA, FS can be used as an alternative for CS in some cases but not all. FS can only express the first three of these relationships, and the last two must be expressed using CS, as shown in (2). Moreover, there is some limitation when it comes to FS expressing possession, notably, FS cannot express a kinship relation or inalienable possession (body parts), as shown in the examples (3)-(5). However, there are cases where FS is preferred. In the rest of this section, we describe the different situations where FS is preferable.

FS can be used to ease reading or comprehension by breaking the string of embedded adjectives in a CS or to avoid ambiguity. It was mentioned above, that both the CS head and its genitive complement can be modified by an adjective and that the adjective of the complement comes before the one modifying the head. Also, it was mentioned that because case is covert, in HA, and no morphological markers are present, the 
meaning of CS can be ambiguous, unless the head and complement nominals have contrasting gender and/or number. Consider these examples:

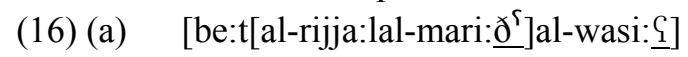

House (M.SG) the-man (M.SG) the-sick (M.SG) the-wide (M.SG)

"the sick man's wide house" [lit. the wide house (the) one (of) the sick man]

(b) [[al- be:tal-wasi:@] $]\left[\right.$ hagg[al-rijja:lal-mari: $\underline{\left.\left.\left.\delta^{\Upsilon}\right]\right]\right]}$

the-house (M.SG) the-wide (M.SG) ANAPH the-man (M.SG) the sick (M.SG)

"the wide house of the sick man" [lit. the wide house (the one) belonging to the sick man]

(17) (a) [be:t[al-rijja:l al-kabi:r]] OR [[be:tal-rijja:l]al-kabi:r]

House (M.SG) the-man (M.SG) the-big (M.SG)

"the big man's house/ the man's big house"

(b) [al- be:t $[$ hagg[al-rijja:lal-kabi:r]]]

the-house (M.SG) ANAPH the-man (M.SG) the-big.m.s

"the house of the big man"

(c) [[al-be:tal-kabi:r][ haggal-rijja:l]]

the-house (M.SG) the-big (M.SG) ANAPH the-man (M.SG)

"the big house of the man"

The long string of words and nesting embedded adjectives, in (16a), make it difficult to understand the intended meaning, especially if there are more than two embedded CSs, each of which is modified by an adjective. On the other hand, by using FS, as in (16b), it is easier to understand the phrase. In (17a), there are two readings to the phrase because both nouns carry the same phi-features and the adjective is compatible with both of them. Moreover, as there are no overt morphological markers, it is hard to determine which noun the adjective refers to. However, the two examples $(17 \mathrm{~b} \& \mathrm{c})$ are straightforward in an FS structure.

FS is not only preferred to break up strings of embedded adjectives, but also as an alternate to strings of multiple embedded CSs. One of the characteristics of CS is multiple embedding. There is no maximum number, hence, the more embedded they are, the harder is the sentence to parse. FS can solve this problem by breaking such a phrase into smaller chunks even though the FS functions as a CS, see (18):

(18) (a) [CS1 ba:b [CS2 sayya:r-at [CS3 $\underline{\text { s}}$ ahib [CS4 waladal-j:ira:n]]]] door car friend son the-neighbours

"the neighbours' son's friend's car door"

[lit. (the) door (of the) car (of the) friend (of the) son (of) the neighbours]

(b) [CSba:b [al-sayya:rah][CS1 hagg [CS2 $\underline{s}$ 'a ahib [CS3 waladal-ji:ra:n]]]]]

door the-car ANAPH friend son the-neighbour

"the door of the car belonging to the neighbours' son's friend"

[lit. (the) door [(of) the-car ${ }_{i}$ [(the) one $e_{i}$ [(of) (the) friend [(of) (the) son (of) the-neighbour]

In (18a), there are four CSs. The phrase is difficult to construct and difficult to parse. However, in (18b), the same proposition is expressed using the FS which makes it easier to understand. Note that each CS in this structure is definite because it inherits definiteness by virtue of its relationship with its complement. Also, note that $\hbar a g g$ also inherits the definiteness feature of its complement.

Another situation where the FS is preferred is with emphasis. The main stress is shifted from the head noun in the CS to the genitive noun in the CS phrase (see Al Barrag, 2014 among many others; Al Sharifi \& 
Sadler, 2009; Borer, 1999; Hazout, 2000; Kremers, 2005; Owens, 2006). It is the same semantically. Thus, to emphasize the head noun, one can use the FS which is more like topicalisiation.

(19) (a) $\underline{\text { ?aft }}$ 'i:-ni kita:b al-walad give-me book the-boy

"Give me the boy's book"

(b)

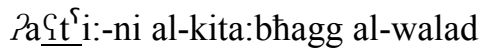

$$
\begin{aligned}
& \text { give-me the-book ANAPH the-boy }
\end{aligned}
$$

The same meaning is conveyed by the two sentences in (19) using CS and FS respectively. However, there is more emphasis on al-kita:b "the book" in (19b).

\section{Conclusion}

This paper discusses the FS in HA as an alternative to CS; a structure that is not used in MSA. It was introduced into the Arabic dialects later on. This paper firstly discusses the characteristics of this structure in comparison to its counterpart the CS. It has been shown that FS can express only three semantic relations out of the five that CS can convey. Moreover, it has been shown that the FS genitive exponent in HA hagg agrees with its antecedent in phi-features. In the second section, the discussion shows the origin of the genitive exponent $\hbar a g g$ as a noun that has acquired a new meaning. Different analyses for $\hbar$ agg have been introduced by different scholars including our analysis. We have argued that $\hbar a g g$ is a noun that has acquired a new meaning: an anaphor that means something like "one of" and that $\hbar a g g$ heads its own CS; and that it is linked to the preceding DP by a binding relationship, which involves feature agreement in gender and number. Consequently, we have proposed that $\hbar$ agg-headed CS has the same structure of the nominal CS. Finally, we have considered the occurrence of both FS and CS structures in HA and investigated the conditions when one structure is preferred to the other.

\section{References}

Al Barrag. T. (2007). Relative clauses in Hijazi Arabic (M.A. dissertation, University of Queensland, Brisbane).

Al Barrag, T. (2014). Noun phrases in Urban Hijazi Arabic: A distributed morphology approach (Ph.D. thesis, The University of Queensland, Brisbane).

Al Sharifi, B., \& Sadler, L. (2009). The adjectival construct in Arabic (pp. 26-43). Proceedings of the LFG09 Conference, Stanford University, Stanford.

Al Zahrani, M. (2008). Morphology of negation in Modern Standard Arabic and spoken Hijazi Arabic (M.A. thesis, University of Queensland, Brisbane).

Al Zahrani, M. (2013). Morphosyntactic and semantic properties of Hijazi Arabic modals (Ph.D. thesis, University of Queensland, Brisbane, Queensland).

Al Zahrani, M. (2014a). Negation in non-verbal clauses-Modern Standard Arabic (MSA) and Spoken Hijazi Arabic (SHA). Pakistan Journal of Languages and Translation Studies, 2, 31-49.

Al Zahrani, M. (2014b). The syntactic properties of negatives. US-China Foreign Language, 1, 1-17.

Al Zahrani, M. (2015). Reflexives and reciprocals in classical and Hijazi Arabic. Pakistan Journal of Languages and Translation Studies, 1, 28-43.

Aoun, J. (1978). Structure interne du syntagme nominal en Arabe: L'Idafa. Analyses the'Ories, 2, 1-40.

Bardeas, S. M. (2010). The syntax of the Arabic DP (Ph.D. thesis, The University of York, UK).

Borer, H. (1999). Deconstructing the construct. In K. Johnson and I. Roberts (Eds.), Beyond principles and parameters (pp. 43-89). Dordrecht: Kluwer. 
Brustad, K. (2000). The syntax of spoken Arabic: A comparative study of Moroccan, Egyptian, Syrian and Kuwaiti dialects. Washington, D.C.: Georgetown University Press.

Fassi Fehri, A. (1993). Issues in the structure of Arabic clauses and words. Dordrecht: Kluwer Academic Publishers.

Feghali, H. (1991). Arabic Hijazi reader. Wheaton: Dunwoody Press.

Harning, K. E. (1980). The analytical genitive in the modern Arabic dialects. Stockholm: Acta Universitatis Gothoburgensis.

Hazout, I. (2000). Adjectival genitive constructions in Modern Hebrew: A case study in coanalysis. The Linguistic Review, 17, $29-52$.

Kheshaifaty, H. (1996). Numerals: A comparative study between Classical and Hijazi Arabic. King Saud University, 9(1), 19-36.

Kremers, J. M. (2005). Adjectival constructs in Arabic. Linguistische Berichte, 203, 331-348.

Margaret, O. (1975). Saudi Arabic urban Hijazi dialect basic course. Washington, D.C.: Foreign Service Institute.

Mohammad, M. A. (1999). Checking and licensing inside DP in Palestinian Arabic. Perspectives on Arabic Linguistic, 12, 27-44.

Nydell, M. K., \& Foreign Service Institute (U.S.). (1975). Saudi Arabic urban Hijazi dialect: Basic course. Washington: Foreign Service Institute, Dept. of State: for sale by the Supt. of Docs., U.S. Govt. Print. Off.

Owens, J. (2006). A linguistic history of Arabic. Oxford: Oxford University Press.

Ritter, E. (1987). NSO noun phrases in Modern Hebrew. Paper presented at The Proceedings of the North East Linguistic Society (NELS), University of Massachusetts, Amherst.

Ritter, E. (1988). A head movement approach to construct-state noun phrases. Linguistics, 26(6), 909-929.

Ritter, E. (1991). Two functional categories in noun phrases: Evidence from Modern Hebrew. In S. D. Rothstein (Ed.), Perspectives on phrase structure: Heads and licensing (pp. 37-62). San Diego: Academic Press.

Ryding, K. C. (2005). A reference grammar of modern standard Arabic. Cambridge: Cambridge University Press.

Shlonsky, U. (2004). The form of Semitic noun phrases. Lingua, 114, 1465-1526.

Sieny, M. (1978). The syntax of urban Hijazi Arabic. London: Longman.

Siloni, T. (1997). Noun phrases and nominalization: The syntax of DP. Dordrecht: Kluwer Academic Publishers. 